\title{
TRAILER PARK RESIDENTS: ARE THEY WORTHY Of SOCIETY’S RESPECT?
}

\author{
STEVEN T. ANDERSON \\ University of North Dakota
}

\begin{abstract}
Existing research is limited in explaining the existence of and reasons for stereotypes held against trailer park residents. This study uses an experimental design to measure attitudes towards trailer park residents, specifically in terms of being considered worthy of society's respect. An Internet questionnaire was designed and administered to a sample of 559 introductory sociology students at a Midwestern university using semantic differentials to measure attitudes towards a fictitious couple. Participants were divided into a control and an experimental group. The groups were presented with two different vignettes, which were the same except for the experimental group, for which the vignette contained the term trailer park as a descriptor. The results indicated that differences between the control group and the experimental group on several measures were significant. The results supported the hypothesis that those who live in trailer parks were deemed less worthy of society's respect by college students. In conclusion, the findings support the notion that people who live in trailer parks have been singled out in American culture for denigration.
\end{abstract}

\section{Introduction}

Whether reading the newspaper or watching the news, stories of racial conflicts and economic disparity abound. Simon (2016) suggests that conflict between groups produces a great deal of misery and frustration - particularly for those who belong to a

Steve Anderson, MA (steven.t.anderson@ndus.edu) is a sort of Renaissance man. After retiring, he decided to go back to school and complete the bachelor's degree he abandoned forty years earlier due to family and work responsibilities. He loved learning and decided to attend graduate school, earning a master's degree in sociology. 
marginalized or stigmatized group. America was founded on the principle that "all men are created equal" (Jefferson 1776), suggesting that all people are deserving of respect and fair treatment. Unfortunately, we do not always treat those we deem inferior with respect.

Simon (2016) suggests that those stigmatized by society are shunned, humiliated, shortchanged, and exploited. He concludes that they know they are being mistreated and resent it. In a recent qualitative study of mothers within a trailer park, one of the participants, a mother of three, described the stereotypes she believed others had about her and those like her when she said, "If you live in a trailer park, you're on welfare, use drugs, and are a bad parent - automatically" (MacTavish 2007:74). To understand the motivation of this study, it is important to understand the example of this woman. She is a person who may be viewed as less worthy, less deserving, and looked down upon by society. At the same time, she understands that she bears no resemblance to these stereotypes (MacTavish 2007). The purpose of this study is to determine whether a predominantly negative attitude towards trailer park inhabitants exists using an experimental survey design.

One of the least understood and researched groups that are part of the underclass are trailer park residents. Approximately ten percent of the total housing stock in America is made up of trailer houses, and roughly half of those living in a trailer house also reside in a trailer park (National Consumer Law Center 2008). So far, little research has been done to quantify the level of prejudice that exists toward those who live in trailer parks. Media portrayals in television shows such as Trailer Park Boys and COPS depict a group of people on the fringes of society, engaged in illicit drug use and criminal activities. However, social psychologists have conducted little research about trailer park residents. This paper proposes to investigate whether prejudices and stereotypes held about trailer park residents exist among American young adults in the Midwest. One assumption of this paper is that study participants' attitudes resemble the entirety of American society (Smith 2002) because, as stated by social judgement theory, attitudes are made up of stimuli from the environment.

Social judgement theory describes an individual's attitude and its potential for change as a judgement process (Chau et al. 2014). 
Theory suggests people determine their behavior towards each other based on interaction with a variety of individuals and groups. Normative descriptors of a specific social group are formed and passed on verbally and non-verbally (Hogg and Reid 2006). Social group members believe they are entitled to the values and positive emotions associated with their group. Included in this is the right to perceive themselves as superior to other social groups (Brown 2010).

Based on social judgement theory, this paper theorizes that the term trailer park causes some sort of reaction from individuals. As such, this paper employed an experimental survey design focusing on the key term - trailer park. Survey participants were split into control and experimental groups and asked to rate a fictitious couple. Two different scenarios were presented. Within the scenarios, all things were equal except where the term trailer park was used in the experimental group. This experimental survey design is meant to test the hypothesis that those living within trailer parks will be deemed less worthy of society's respect (MacTavish, Notter, and Shamah 2008).

\section{A Brief History of Trailer Parks}

Although the proper terms for a trailer park and trailer are manufactured home community and manufactured home, the derogatory terms trailer and trailer park still permeate society (Saatcioglu and Ozanne 2013). For this study, the derogatory terms will be used because they are believed to be more recognizable by those participating in this study when considering the research question. This type of housing serves as the largest supply of unsubsidized affordable housing in the country (Consumer Financial Protection Bureau 2014). Over 22 million Americans call a trailer home - home. Roughly half of those residing in trailer parks are over 55 years of age (Hoyt 1954; Bureau 2017).

The negative association between trailer parks and those on the lower strata of economic society began during the Great Depression (Saatcioglu and Ozanne 2013). They symbolized the vagabond nature of a traveling society seeking scarce employment. During the 1940s and 1950s, the homes were still mobile, but began to contain the features found in a site-built home and became more permanent in nature. Today's trailer house is built of high-quality materials that 
rival site-built homes. At the same time, they are typically less mobile than their older counterparts. Less than one percent of the more modern homes are relocated once transported to a site due to the high cost and specialized equipment needed to relocate a home (Consumer Financial Protection Bureau 2014).

\section{Literature Review}

This section covers the theoretical perspective behind this paper, existing attitudes and stereotypes, how trailer park residents are depicted in the media, and how these stereotypes reinforce stratification.

\section{Theoretical Perspective}

The basic premise of social judgment theory suggests that an individual's attitude and its potential change is a judgment process (Chau et al. 2014). It was formally introduced in the 1960s as a theory designed to study how people evaluate and change their behavior - based on interactions with others. Group norms are defined as regularities in attitudes and behaviors and shape perceptions of a specific social group, including how groups may be different from other social groups (Hogg and Reid 2006). Social judgment theory suggests that the human attitude spectrum consists of three latitudes: acceptance, indifference, and rejection (Siero and Doosje 1993). When a person receives a message, they respond in one of three ways. The first latitude is the level of acceptance, determined by how much the person agrees with the message. Second is the latitude of non-commitment, in which the person neither agrees nor disagrees. The final latitude is that of rejection, in which the person disagrees with the message being expressed.

Social judgment theory is ecological because it is not encapsulated within an individual (Siero and Doosje 1993). It calls for attention to both internal and external environments that provide various stimuli that affect the decision-making process. For example, if a message is consistent with a person's belief system, it is within their latitude of acceptance (Chau et al. 2014). A contrary message is within the individual's latitude of rejection and everything in between is in the latitude of non-commitment. Putting it in more simple terms, the more closely a message matches a person's belief system, the greater the possibility it will be accepted. 
The bedrock principle of social judgment theory is that a person cannot possess absolute knowledge about their environment (Siero and Doosje 1993). Through both verbal and non-verbal communication methods, normative descriptors of a specific social group are both formed and passed on (Hogg and Reid 2006). Putting it more succinctly, when we learn something, we pass it on to those within our sphere of influence (Covey 1992). Those we share things with pass that information to those within their sphere of influence until the message permeates society. From there a person develops a belief that they are part of a specific social group and are entitled to the values and positive emotions associated with that group (Hogg and Reid 2006). Included in this is the right to perceive themselves as superior to other social groups (Brown 2010).

This results in categorizing people based on the person's representation of a certain group that is outside their group in a context-dependent prototype (Hogg and Reid 2006). Group prototypes specify how people feel, think, and behave towards social groups different from their own. These prototypes are shared with those within the "in-group" to describe the characteristics of the "out-group." These prototypes may or may not be based on actualities, and usually contain degrees of inaccuracy.

The perceived "groupness" of a social category serves to facilitate stereotyping (Brown 2010). This is based on a perception that members of that social group are less worthy of respect than others and possess either a single attribute or a set of attributes, such as being on welfare or taking illicit drugs. This leads to a person's judgment of another based on stereotypes. People make judgments of other people based on a variety of criteria, including respectability. Some judgments are accurate, while others are based on inaccuracies emanating from a variety of sources. The most common thing people do when judging others is look on the person they are judging in a more negative light (Wrightsman 1992). These negative perceptions may be indicative of society's definition of who belongs (MacTavish 2007).

Stereotypes arise from the belief that most members of a group, such as trailer park residents, share common attributes (Brown 2010). Such stereotypes may arise from inferences that people make about the psychological attributes of the group being targeted. They may also be used as ideologies designed to maintain the status quo. 
Stereotypes act as mental shortcuts designed to speed up investigating the depth of each person, we encounter (Brown 2010).

Being perceived as someone who does not belong is bound to impact a person's self-esteem. Self-esteem is a primary factor when it comes to performance (Boucher and Rydell 2010). The lower one's self-esteem, the lower one performs. Self-esteem and performance are directly linked to stereotypes. Members of groups identified with negative stereotypes and deemed less worthy of society's respect usually possess a lower self-esteem than those identified with a more positive stereotyped group. At the same time, negative stereotypes are often used unfairly and create negative outcomes for those who are the subjects of these attitudes (Duguid and Thomas-Hunt 2015).

Prejudices are expressed as the subsequent behaviors based on the emotions of individuals towards a group of people (Smith 2002). They emanate from expressed and taught behavior, especially from childhood. As with racial prejudices, attitudes towards those who perceive themselves as superior are passed down from generation to generation, typically while children are very young (Brown 2010). Such passing down of perceptions of superiority is essential in forming a caste system in our society based on social status (Alexander 2012).

As applied to this study, existing research suggests trailer park residents may be considered inferior to other groups by society (Harry 2006). Social judgment theory comes into play because the mere image of a trailer park may signal that trailer park residents are members of an "out group" due to learned patterns of thought passed from one generation to the next. These judgements are based on ideas related to home ownership. The purpose of this study is to determine the extent and degree stereotypes come into play when considering trailer park residents. Qualitative and quantitative studies of trailer park stereotypes have explored the subject from both the trailer house owner's perspective and the general public's perspective. All the studies reviewed suggest these attitudes exist (Bali and Davis 2008; Barthe, Leone, and Stitt 2014; Center 2015; Consumer Financial Protection Bureau 2014; Edwards, Klemmack, and Hatos Jr. 1973; Harry 2006; Hill 1999; Hoyt 1954; MacTavish 2007; MacTavish, Notter, and Shamah 2008). This paper seeks to quantify the relationship between housing choice and how that 
choice is viewed by society. A gap exists in current research that fails to document quantitatively people's attitudes regarding how trailer park residents are viewed by society.

\section{Social Distinction and Home Ownership}

A home is thought to be a marker of social distinction (Saatcioglu and Ozanne 2013). This holds true for the traditional site-built house. The larger the home, the more social distinction a person is believed to possess. In a typical trailer park, "social perceptions are engineered for the comfort of those whose economic limits prevent them from buying what middle class people call a 'real home'" (Hill 1999:225). The typical buyer of a trailer house is looking for social, not physical, mobility. The industry itself promotes a dream of home ownership by offering amenities once thought available to only those who are perceived as attaining a higher social class at a more affordable price (Saatcioglu and Ozanne 2013; Hill 1999). Despite containing many features and innovations that rival site-built homes, these homes and those who occupy them are subjected to ridicule. When first introduced during The Great Depression, trailer parks were thought of as a temporary place to concentrate those wandering from place to place looking for work (Saatcioglu and Ozanne 2013) and whose residents were unfit to be around "proper people." The end of World War II brought about different perceptions of trailer homes, trailer parks, and those that lived within them, which was not necessarily an improvement.

\section{Affordable Housing and Trailer Park Stereotypes}

Trailer parks are considered part of the affordable housing equation by many affordable housing advocates because they are part of the solution for achieving the "American dream" for those with low to moderate incomes. These advocates often face significant opposition when it comes to affordable housing based on the perceived character of future residents (Tighe 2012). Residents living within non-poor areas are apt to protest any affordable housing project, including trailer parks (Tighe 2012). The basic elements of the stereotypes against affordable housing projects consist of increased crime, a sense that affordable housing programs are giveaways, concern for decreased property values, and lack of aesthetic appeal (Belden and Russonello 2003). 
Along with existing stereotypes towards affordable housing, additional stereotypes are directly associated with residents of trailer parks (Newitz and Wray 1997). The homes themselves have been categorized as magnets for tornados, poor white trash, and macaroni and cheese, which is symbolic of a lack of sophistication (Harry 2006). Trailer park residents are equated with unskilled labor when compared to skilled craftsmen (Kumar 2004). The terms "trailer trash" or "trailer park trash" are still prominent in society and are synonymous with the term "white trash" (Harry 2006). White trash consists of two components: white, which is based on race, and trash, something that needs to be discarded for whiteness to continue as the dominant race and culture (Newitz and Wray 1997). Stereotypes associated with trailer park residents and racial minorities contain many similarities.

The negative stereotypes associated with trailer park residents is reflective of linguistic intergroup bias, which becomes evident when expressed through different mediums. For example, the proper name for a trailer park is a manufactured home community. In many media depictions, it is still called a trailer park. This type of bias is often considered automatic and, despite any new information, is almost impossible to dispel. This is further illustrated by the example of former president Bill Clinton. Among his many public relations problems, he was routinely portrayed by his detractors as "trailer trash," i.e. a person who is impulsive, shiftless, and lascivious with no moral self-restraint (Thompson and Tian 2008).

Those who are poor or of limited means are often depicted negatively by the media. News magazine photographs are often the only things viewed and remembered by readers who typically skim through a magazine and rarely read it cover to cover (Newitz and Wray 1997). The term "trailer trash" emanates from an amalgam of visual images that reinforce commonly-held perceptions. Trailer park residents have long been depicted as ones deserving low social esteem when it comes to social standing, possessing a series of negative cultural habits and interests (Harry 2006). Many poor whites are caricatured as "poor white trash," "trailer trash," "rednecks," and "crackers" (Jones 2009). They are denied the socioeconomic benefits afforded to more prosperous whites. Although whiteness often suggests power and influence; "trailer trash" lose much of their "whiteness" and share many of the same 
experiences associated with racial and ethnic minority groups, including African-Americans and Hispanic/Latino populations (Jones 2009).

In a qualitative study of mothers and children who live in a trailer park one teenage resident described the stereotypes he often encountered, "Some parents think my parents must be doing drugs. My parents aren't like that, but they know where I live” (MacTavish 2007:74). Trailer parks are often viewed as havens for poor urban whites (Desmond 2012). Yet, most trailer parks are located within standard metropolitan statistical areas (French and Hadden 1965).

Indeed, negative perceptions do not always match reality. For example, a 1996 study found that the average manufactured home buyer was between 40 and 49 and was a white-collar professional (Harry 2006). Another study by Barthe, Leone, and Stitt (2014) concluded that those living in a trailer park do not create significant crime problems. The authors contend that trailer home owners live near one another and feel the need to maintain the peace as their housing options are limited, especially considering the insecurity that comes with trailer park residency (Aman and Yarnal 2010). This runs contrary to the myth that trailer parks are crime ridden (Harry 2006).

\section{Resulting Stratification}

Stereotypes, even if inaccurate, lead to stratification. Power, wealth and status are thought of as the primary dimensions of stratification (Bowles 2013). Put simply, these variations lead to significant differences in power resources between classes favoring those with the greater degree of power resources, typically the well off (Dirlam and Jacobs 2016). Stratification comes into play because many former welfare recipients are now working in lowand moderate-income jobs. They live in trailer homes as part of an effort to improve their social standing (Latimer and Woldoff 2010). They typically gain nothing in the process. Trailer park residents are vulnerable for a variety of reasons, including loss of value after purchase of their home. In addition, space rents have experienced continuous increases, despite the recent recession, and are consigning those of low and moderate incomes to financial ruin (Desmond 2012). 
Stereotypes separate one group from another through use of specific characteristics that other individuals do not have (Judd and Park 1993). Evidence for this comes from lobbying efforts against affordable housing projects by community activists who claim the projects would lead to an increase in crime, drug use, and other negative outcomes (Tighe 2012). Katherine MacTavish (2007) studied how students from a town of 8,000 in Oregon bussed all the children from the community's five trailer parks to a school on the edge of town. She noted that the town concentrated all children from low- and moderate-income families into a single school. MacTavish contended that such actions reinforce negative perceptions of trailer parks and their residents. Part of this includes attitudes that trailer parks are a drain on the community's limited resources. Such stratification suggests that trailer park children do not possess the same academic capacities as their more affluent counterparts and require "special help" (Brown, Lesane-Brown, and Tanner-Smith 2009).

Deeming a group less worthy of society's respect is one element of creating a caste, resulting in a measure of control towards trailer park residents that range from the non-existence of laws protecting trailer park residents from potential abuses to exclusionary laws and policies that favor the land owners with no reciprocal protections for the person who owns a trailer home residing on the land owner's property. In most states, trailer park residents are easily evicted and their homes taken from them with no remuneration (Center 2015). Such measures of control are designed to relegate trailer park residents to a low socio-economic status with no opportunity for societal advancement.

The precarious situation for those of low to moderate incomes comes into focus when considering how local governments use urban gentrification as a mode of exclusionary eminent domain (Dana 2009). This occurs in large cities with a mix of wealthy and poor neighborhoods in gentrified areas. The cities condemn large areas - basically forcing the poor to either concentrate in remaining poor areas or leave. State and local zoning laws enhance the ability of local governments to rezone trailer parks out of existence in cities and townships (Worden 1963). The end result is that many cities are using zoning regulations to put trailer parks out of business, and there is little residents can do to stop the process (Latimer and 
Woldoff 2010). The result of the precarious nature of a trailer park resident is an uneven distribution of resources that typically favor the well-off, leaving them with esteem issues (Boucher and Rydell 2010; Dirlam and Jacobs 2016).

Trailer park home owners are denied basic constitutional rights in several states - including North Dakota (Center 2015). Additionally, although the cost to purchase a trailer home is less than the cost of a site-built home, banks charge interest rates that are four to five times higher than rates for a site-built home for terms of 20 years or less (Consumer Financial Protection Bureau 2014). Efforts to change these policies have been met with substantial resistance, particularly when it comes to trailer park residents (Federal Housing Finance Agency 2016).

This research adds to the literature by quantitatively measuring the attitudes of people towards trailer park residents. Although the examples above illustrate their potential existence, this study seeks to verify and confirm this phenomenon. Bearing this in mind, the hypothesis is that college students will rate those living within trailer parks less worthy of society's respect compared to those living in other types of housing.

\section{Methods}

The basic research question of this paper is whether people view trailer park residents as less worthy of society's respect. To answer this question an experimental survey was used to measure the latitude of prevailing attitudes towards those who live in trailer parks (Siero and Doosje 1993). This was accomplished by surveying introductory sociology students at a Midwestern university in the fall 2016 semester. Students completed an online questionnaire between September and October. The survey design called for participants to be split into two groups: a control and an experimental group. The control group was asked to rate a fictitious couple based on several criteria using a semantic differential scale after reading a vignette describing the attributes of the couple except their mode of housing. The experimental group had the same vignette except the term trailer park is used as the couple's housing choice. Additional information gathered in the survey included basic demographic information about respondents, such as race/ethnicity, gender, year of school, social class, life in the United States. 
After conducting listwise deletion of missing data, the sample size is 559 undergraduate students out of a potential sample of 724 undergraduate students. The total response rate was 77 percent. Because the data were gathered from a convenience sample, the statistical outcomes are preliminary in nature.

\section{Dependent Variables}

In the case of this experiment, the text of the vignette was the same except for where the couple live. The first vignette has a couple living in a trailer park, while in the second vignette the type of housing is unspecified. The remaining components of both vignettes are as follows: "Bob and Mary are a married couple in their 20s with two children under 10 years old. Bob works as a customer service manager at a big box retailer and is currently taking one class at a community college to see if he likes it. Mary graduated from high school and works part-time at a convenience store when Bob is off work. Bob drives a pickup truck and likes to hunt and fish while Mary likes to play cards and visit with her friends. Bob and Mary live [in a trailer park] on the outskirts of Omaha."

Survey respondents then rated their perceptions of Bob and Mary by answering several questions. Word combinations such as good vs bad are used to measure the respondent's responsiveness to different word combinations for semantic differentials (Jenkins, Russell, and Suci 1958). These questions included:

1. How worthy are Bob and Mary of society's respect? Unworthy $=0$ vs Worthy $=100$

2. How would you rate Bob and Mary when it comes to? Foolish $=0$ vs Wise $=100$

3. How would you rate Bob and Mary when it comes to? Dirty $=0$ vs Clean $=100$

4. How would you rate Bob and Mary when it comes to? Lazy $=0$ vs Hard Working $=100$

5. How would you rate Bob and Mary when it comes to? Dumb $=0$ vs Smart $=100$

6. How would you rate Bob and Mary when it comes to? Immoral $=0$ vs Moral $=100$

7. How would you rate Bob and Mary when it comes to? Drunk $=0$ vs Sober $=100$ 
To obtain as accurate a measurement as possible a semantic differential scale was employed to determine a value for these interval ratio variables. The survey itself had a sliding bar where respondents moved the bar between both words with the numeric value recorded but not visible to the participant. In previous studies, such a scale proved better than Likert versions in terms of model fit and unidimensionality when individual attitudes are being measured (Friborg, Martinussen, and Rosenvinge 2006). Ratings with 5-point scales are troubled by shared ranks and a low degree of differentiation between aspects on the individual level (Funke and Reips 2012). The ability to detect small differences creates far more possibilities for data analyses when using this type of rating scale.

The primary dependent variable used here is the question regarding Bob and Mary's worthiness of society's respect. All the other variables are illustrative variables that provide additional clarification by providing information about the various stereotypes associated with trailer park residents and how they relate to the question of worthiness of society's respect.

\section{Independent Variable}

The independent variable, group, represents the random assignment of survey participants to either the control or experimental group. An important aspect of this experiment was to ensure the experimental and control group was relatively evenly split and that it was done at random. This was accomplished with the survey software that assigned participants to the groups randomly into two groups; experimental $=0$ and control $=1$. The control group was assigned the vignette where Bob and Mary lived on the outskirts of Omaha. The experimental group involved the vignette where Bob and Mary lived in a trailer park on the outskirts of Omaha.

\section{Control Variables}

Since other sociodemographic characteristics may influence the likelihood of expressing stereotypes, I control for the following variables: gender, race and ethnicity, year in college, and length of time in the United States.

Gender was coded Male $=1$ and Female $=2$. Race/ethnicity was recoded as White $=1$ and Non-White $=0$. The length of time in the United States was coded (1) less than 5 years; (2) 5 to 10 years; (3) Over 10 years; and (4) All my life. The question, "What is your 
social class background?” was coded (1) lower class; (2) working class; (3) middle class; (4) upper middle class; and (5) upper class. Four answers ( 0.7 percent) were system missing. The year of college variable was coded as (1) Freshman; (2) Sophomore; (3) Junior; (4) Senior; and (5) Graduate Student. A total of six respondents (1.1 percent) were listed as system missing. "Other" responses were recoded as "system missing." Missing data were not included in the data analysis.

\section{Reliability and Validity of Data}

The survey was coded so that the same IP address was unable to take the survey more than once, helping to prevent identical answers and multiple attempts. The two instructors of these classes offered their students extra credit for participating in the survey. Each record was assigned a unique identifier.

\section{Pre-Testing}

A pre-test was performed in May 2015 using an interval scale to measure the social standing of the fictitious couple in both vignettes. The sample indicated the possibility of a contrast between the two vignettes; however, it was not significant enough to determine this empirically. It was determined after the pre-test that a scale of 0 to 100 would be a more effective measurement standard (Creswell 2014).

A second pre-test was performed in August 2016. This test employed the sliding scale. The initial data appeared to show significant differences between the two vignettes. It also suggested that housing choice was a significant factor shaping respondent's answers to the initial question. As part of the pre-test, respondents were interviewed after taking the survey for their feedback. Names were not recorded, and the respondents were selected at random during lunch time at the University's Memorial Union. Some of the comments include the following:

- I rated them as thrifty because they lived in a trailer-park and carefree for the same reason.

- Education should be finished before a couple decides to have a child.

- Living in a trailer-park is harder on kids because they work harder than other kids to get a good education. 
- The lifestyle in a trailer-park is very aggressive where kids grow up to be their parents.

- The couple seem like a normal-average American family.

- He is in a routine and taking a college class suggests he is trying to change it.

- I tried to fight through my own prejudices.

- I tried to imagine myself in their condition.

\section{Data Analysis and Interpretation}

Data were downloaded from the university's server to the researcher's personal computer, which is double-password protected. The data were analyzed using the university's shared license of the SPSS statistical software program. The initial analysis was comprised of a series of $t$ tests, based on seven dependent variables. A baseline ordinary least squares (OLS) regression was performed to determine the strength of the group variable's relationship to the primary dependent variable - worthiness of society's respect. A second OLS regression was performed using all independent variables (group, gender, race/ethnicity, life in the U.S., year in school, and social class background) to determine if the group variable remained significant after controlling for these factors.

\section{Ethical Considerations}

Once the dataset was downloaded, the survey was closed and not accessible to anyone except the researcher and advisor. The exclusion and deletion of IP addresses promoted the anonymity of survey participants. The unique record identifier randomly assigned to each record has nothing to do with an individual's identity. Any other potential information that may be used to identify study participants was deleted.

\section{Results}

When examining and interpreting the results, the main thing to remember is that this is an experiment involving college student's judgment of people in which the only difference between the experimental and control group is the use of the term "trailer park" in one of the vignettes. As shown in Table 1, the division between the experimental and control group is relatively even with 49.73 percent of respondents in the experimental group and 50.27 percent 


\begin{tabular}{|c|c|c|c|}
\hline Variables & & $N$ & $\%$ \\
\hline \multirow[t]{2}{*}{ Group } & Experimental & 278 & 49.7 \\
\hline & Control & 281 & 50.3 \\
\hline \multirow[t]{4}{*}{ Life in the US } & Less than 5 years & 15 & 2.7 \\
\hline & 5 to 10 years & 6 & 1.1 \\
\hline & Over 10 years & 33 & 5.9 \\
\hline & All my life & 499 & 89.3 \\
\hline \multirow[t]{5}{*}{ College Year } & Freshman & 351 & 62.8 \\
\hline & Sophomore & 113 & 20.2 \\
\hline & Junior & 61 & 10.9 \\
\hline & Senior & 25 & 4.5 \\
\hline & Grad Student & 3 & .5 \\
\hline \multirow[t]{2}{*}{ Gender } & Male & 204 & 36.5 \\
\hline & Female & 348 & 62.3 \\
\hline \multirow[t]{5}{*}{ Social Class } & Lower Class & 8 & 1.4 \\
\hline & Working Class & 62 & 11.1 \\
\hline & Middle Class & 250 & 44.7 \\
\hline & Upper Middle Class & 210 & 37.6 \\
\hline & Upper Class & 25 & 4.5 \\
\hline \multirow[t]{2}{*}{ Race } & Non-White & 70 & 12.5 \\
\hline & White & 489 & 87.5 \\
\hline
\end{tabular}

in the control group. To better understand this experiment, it is important to have a basic understanding of the survey participants by reviewing descriptive statistics regarding them.

In this study, 82 percent of the participants indicated they came from either a middle-class or upper-middle-class background. The clear majority of study participants - roughly 95 percent - were either lifelong or more than ten-year residents of the United States. Approximately 83 percent of respondents were either in their freshman or sophomore year of college. This is desirable because of the earlier contention that students in their first or second year of college are likely to maintain the values and attitudes that existed in 


\begin{tabular}{|c|c|c|c|c|c|}
\hline \multirow[b]{3}{*}{$\begin{array}{l}\text { Worthiness of } \\
\text { Society’s Respect }\end{array}$} & \multicolumn{3}{|c|}{ Total Sample $(N=559)$} & \multicolumn{2}{|c|}{$\begin{array}{l}\text { Experimental } \\
\text { Group }(N=278)\end{array}$} \\
\hline & Mean & Std. Dev & Range & Mean & Std. Dev \\
\hline & 61.91 & 27.68 & 100 & 57.71 & 27.68 \\
\hline Foolish vs. Wise & 48.15 & 24.23 & 100 & 44.16 & 24.23 \\
\hline Dirty vs. Clean & 49.37 & 29.05 & 100 & 44.14 & 29.05 \\
\hline $\begin{array}{l}\text { Lazy vs. Hard } \\
\text { Working }\end{array}$ & 53.75 & 30.34 & 100 & 50.21 & 30.34 \\
\hline Dumb vs. Smart & 46.56 & 26.34 & 100 & 42.68 & 26.34 \\
\hline Immoral vs. Moral & 68.33 & 24.19 & 100 & 72.67 & 24.19 \\
\hline \multirow[t]{3}{*}{ Drunk vs. Sober } & 59.93 & 31.50 & 100 & 56.85 & 31.45 \\
\hline & \multicolumn{3}{|c|}{ Control Group $(N=281)$} & \multicolumn{2}{|c|}{$\begin{array}{l}t \text { test Comparison } \\
\text { of Means }\end{array}$} \\
\hline & Mean & Std. & ev & Mean & SE \\
\hline $\begin{array}{l}\text { Worthiness of } \\
\text { Society’s Respect }\end{array}$ & 66.07 & 27. & & 8.354 & $2.32 * * *$ \\
\hline Foolish vs. Wise & 52.10 & 24. & & 7.935 & $2.02 * * *$ \\
\hline Dirty vs. Clean & 54.54 & 30. & & 10.400 & $2.42^{* * *}$ \\
\hline $\begin{array}{l}\text { Lazy vs. Hard } \\
\text { Working }\end{array}$ & 57.26 & 29. & & 7.055 & $2.55^{* *}$ \\
\hline Dumb vs. Smart & 50.40 & 27. & & 7.723 & $2.21^{* *}$ \\
\hline Immoral vs. Moral & 64.04 & 27. & & -8.636 & $2.02 * * *$ \\
\hline Drunk vs. Sober & 62.97 & 31. & & 6.125 & $2.66 *$ \\
\hline
\end{tabular}

Note: $p<.05^{*} ; p<.01^{* *} ; p<.001^{* * *}$

their home environment (Smith 2002). About 88 percent of the respondent referred to their racial/ethnic background as white. Sixtytwo percent of the sample was female.

Respondents were given one of two scenarios, one where Bob and Mary live on the outskirts of Omaha and the other where Bob and Mary live in a trailer park on the outskirts of Omaha. Means and standard deviations were computed for both control and experimental groups and $t$ tests were conducted to compare the means. Mean differences between the control and experimental groups on the dependent variables were statistically significant at the alpha level of $p \leq .05$.

The hypothesis predicted that the experimental group would hold trailer park residents less worthy of society's respect than the 
control group where no form of housing is mentioned. The hypothesis is supported by the analysis. The worthiness of society's respect variable shows $M=57.71(S D=24.194)$ for the experimental group and $M=66.07(S D=27.860)$ for the control group. The $t$ test results showed this mean difference was statistically significant. Of the seven dependent variables, six are considered different components of the stereotypes held against trailer park residents. All the dependent variables, except immoral versus moral, had a mean value that was less for the experimental compared to the control group. For the experimental group, $M=72.67(S D=24.194)$ and the control group $M=64.04(S D=27.860)$.

\section{Regression Analysis}

To test the robustness of these findings, two separate Ordinary Least Squares (OLS) regression analyses were performed. The first model tested the effect of the independent variable (group) on the dependent variable (worthiness of society's respect). The second model included all control variables (group, life in the US, gender, race/ethnicity, year of college, and social class background).

In the full model, the group variable was the only variable that was statistically significant $(B=8.336, p \leq .001)$ in the full model and statistically significant $(\mathrm{B}=8.354, p \leq .001)$ in the baseline model. In the full model, the R square score was 0.035 . Adding the other independent variables to the equation only resulted in a 0.012 increase in the $\mathrm{R}$ square score, which is a small increase in the amount variance explained.

Table 3. Regression Results: Worthiness of Society's Respect

\begin{tabular}{lllll}
\hline \hline Variables & $\begin{array}{l}\text { Model 1 } \\
\text { Base Model } \\
\text { 8.354*** }\end{array}$ & $\begin{array}{l}\text { Model 2 - Full } \\
\text { Model } \\
8.336^{* * *}\end{array}$ & $\begin{array}{l}\text { Standard } \\
\text { Error }\end{array}$ & p Value \\
Group & & 1.830 & 2.330 & .000 \\
Lived in the US & & 1.495 & 2.290 & .425 \\
Year of College & & 3.796 & 1.352 & .269 \\
Gender & & 1.467 & 2.507 & .130 \\
Social Class & & 0.730 & 1.503 & .329 \\
Race/Ethnicity & & & 3.896 & .852 \\
R-Square & .023 & & & \\
$\mathrm{~N}$ & 559 & & & \\
\hline \hline
\end{tabular}




\section{Summary}

The major findings of this research project are discussed in this section. The analysis supported the hypothesis that trailer park residents would be considered less worthy of society's respect by a group consisting primarily of freshmen and sophomore college students. It also demonstrated that all but one of the attributes associated with trailer park residents are consistent with the primary hypothesis. The OLS regression showed that the attribution to either the control or experimental group and their exposure to the term "trailer park" were predictors of attitudes. The control variables failed to demonstrate a significant relationship to the dependent variable.

\section{Discussion and Conclusion}

A long-recognized paradox of the American creed is that while we hold as true the belief that all men and women are created equal, alongside this belief is the stubborn fact that some Americans are thought to be more equal than others. From the perspective of the dominant culture, some Americans are of lesser value and worth than others. When it comes to trailer park residents, the results of this paper indicate that amongst this sample of college students they are not considered as worthy of society's respect.

Social judgement theory aids in understanding how attitudes are formed and are based on various stimuli. Stimuli emanate from a variety of sources including family, media, school, and peer pressure (Hogg and Reid 2006). Social judgement theory supports the notion that study participants received stimuli from sources prior to their coming to college that formed their attitudes towards trailer park residents. Media depictions of trailer parks are typically less than positive and difficult to ignore (Harry 2006). Along with this are stories and legends passed down from generation to generation that depict trailer park residents as "trailer park trash."

Culture provides individuals with the resources (prejudices, stereotypes, etc.) they may take up and use to demean and denigrate others and in so doing attempt to elevate themselves. This is one mechanism by which social stratification is accomplished. The worthiness measure used in this study was believed to be indicative of the stereotypes held towards trailer park residents by the overall society. One conclusion that could be made, based on the 
experiment's results, is that irrespective of typical demographics, such as race/ethnicity, social class background, and education level; young adults hold more negative attitudes towards trailer park residents, which may reflect the attitudes of their families. Where people live ("wrong side of the tracks") and their type of housing ("renting vs. owning") have been recognized as markers of value and worth. These findings suggest that trailer park residents have been singled out in American culture for denigration and disvaluing.

Sociologists have exhaustively studied social stratification in American society, and along any number of dimensions, including the one studied here, respectability and worth. Negative stereotypes are often used unfairly and create negative outcomes for those who are the subjects of these attitudes (Duguid and Thomas-Hunt 2015). Social closure based on housing prevents a person from moving to a place in the stratification system that is commensurate with their true abilities (Adkins and Vaisey 2009), reinforcing inequalities in key resources such as wealth, political decision making, and social capital.

This study adds to the research in social stratification, particularly that which is concerned with cultural understandings of worth and value. The study's findings make a case that stereotypes towards trailer park residents are predominant, despite the claim that a more egalitarian attitude exists on many college campuses. While we suspect that there is a culture-wide prejudice against those who live in or who are associated with trailer parks, the existence of a prejudice against such people has not been studied by sociologists. It is understood that characteristics associated with trailer park residents include dangerous and excessive sexuality, incestuous relationships, uneducated or simple mindedness, impoverished because of their own actions, and products of misguided social policies (Newitz and Wray 1997). This study argues that these stereotypes exist among college students and may apply to the public as well (Smith 2002).

The point of this study was to make an initial effort to document the existence of this prejudice, using a convenience sample of American college students in a survey-experiment design. The results of the study strongly confirmed the existence of such a prejudice among these college students, leading one to hypothesize that a follow-up study on a representative sample of Americans 
would find the same. Although a convenience sample of college students may not accurately reflect the country's population, the study's findings that the normal demographics collected with most studies are not significantly related to the maintenance of stereotypes towards trailer park residents among college students suggests that this study could be repeated on any college campus in America with the same or similar results.

In some states, trailer park residents are denied basic civil rights and access to the financial marketplace (National Consumer Law Center 2008). In many trailer parks, there is an implied sense of fear amongst the residents about being evicted for a minor rule violation. It is my argument that nothing will change until the stereotypes towards trailer park residents no longer exist. Such a change in stereotypes and stratification should lead to a more equitable balance of power between communities, trailer park residents, and park owners.

There are some limitations of this paper. The first is that the immoral vs moral identifier scored lower for the control group than the experimental group, which does not support the study hypothesis. One potential explanation is that the vignette said Bob and Mary were married, had children, engaged in seemingly normal activities and presented a picture of a couple in a stable relationship. This may have influenced survey participants, whereas no mention of the other factors of their relationship may have produced a wider variation. The second limitation comes from the R square score on both regression models, which were both low. This suggests that "group" is only one small factor in people's ranking of the couple in question. The third limitation lies in the use of a convenience sample of undergraduate students, which limits the generalizability of findings.

The assumption of this study was that student attitudes will reflect that of their parents (Smith 2002). Nonetheless, this study needs to be replicated with a representative sample of the entire country. It is hypothesized that such a replication would produce similar results and demonstrate the nationwide presence of negative attitudes towards trailer park residents. Future studies should also identify existing community capitals within trailer parks. Another should focus on potential political, cultural, and social solutions that empower trailer park residents to help level the playing field 
between them and the trailer park owners. Other research could report the benefits and drawbacks of resident owned communities versus investor owned trailer parks.

In conclusion, this study accomplished its purpose of determining whether negative attitudes exist towards trailer park residents. The factors behind these attitudes are unclear and should be researched further by social psychologists. There is limited research about trailer parks and trailer park residents, making it a ripe topic for future research. 


\section{References}

Adkins, Daniel E. and Stephen Vaisey. 2009. “Toward a Unified Stratification Theory: Structure, Genome, and Status Across Human Societies.” Sociological Theory 27(2):99-121.

Alexander, Michelle. 2012. The New Jim Crow. New York, New York: The New Press.

Aman, Destiny D. and Brent Yarnal. 2010. "Home sweet mobile home? Benefits and challenges of mobile home ownership in rural Pennsylvania.” Applied Geography 30:84-95.

Appelrouth, Scott and Laura D. Edles. 2016. Classical and

Contemporary Sociological Theory. Thousand Oaks,

California: Sage Publications, Inc.

Baker, Daniel, Kelly Hamshaw, and Corey Beach. 2011. “A

Window Into Park Life Findings From a Resident Survey of

Nine Mobile Home Park Communities in Vermont.” Journal of Rural and Community Development 6(2):53-70.

Bali, Valentina A. and Belinda C. Davis. 2008. "Examining the

Role of Race, NIMBY, and Local Politics in FEMA Trailer

Park Placement.” Social Science Quarterly 89(5):1175-1194.

Barthe, Emmanuel P., Matthew C. Leone, and B G. Stitt. 2014.

“Trailer Parks as Hotbeds of Crime: Fact or Fiction?” Issues in

Social Science 2(2):1-20.

Belden, N and J Russonello. 2003. "Valuing housing: Public perception of affordable housing in the Chicago region." Chicago: Housing Illinois.

Boucher, Kathryn L. and Robert J. Rydell. 2010. "Capitalizing on Multiple Social Identities to Prevent Stereotype Threat: The Moderating Role of Self-Esteem.” Personality and Social Psychology Bulletin 36(2):239-250.

Bowles, Douglas. 2013. "Toward an Integrated Theory of Social Stratification.” American Journal of Economics and Sociology 72(1):32-58.

Brown, Rupert. 2010. Prejudice - Its Social Psychology. $2^{\text {nd }}$ ed.

Malden, Massachusetts: John Wiley and Sons, Ltd.

Brown, Tony N., Lesane-Brown Lesane-Brown, and Emily E.

Tanner-Smith. 2009. "Investigating Whether and When Family 
Ethnic/Race Socialization Improves Academic Performance.” The Journal of Negro Education 78(4):385-404.

Bureau, US C. 2017. “American Housing Survey - Table Creator.” https://www.census.gov. Retrieved March 3, 2019

(https://www.census.gov/programs-

surveys/ahs/data/interactive/ahstablecreator.html\#?s_areas $=a 00$ 000\&s_year $=$ n2017\&s_tableName $=$ Table1\&s_byGroup1=a15 \&s_byGroup2=a1\&s_filterGroup1=t1\&s_filterGroup2=g1\&s_ show $=\mathrm{SO}$ ).

Center, National C. L. 2015. "Innovations in Manufactured Homes (I'M HOME) - Corporation for Enterprise Development (CFED).” Manufactured Housing Metropolitan Opportunity Profile: Policy Snapshot - Manufactured Home Communities in North Dakota. Retrieved June 17, 2016 (http://cfed.org/assets/pdfs/North_Dakota_Policy_Snapshot .pdf).

Chau, H.F., C.Y. Wong, F.K. Chow, and Chi-Hang F. Fung. 2014. "Social judgment theory based model on opinion formation, polarization and evolution.” Physica A: Statistical Mechanics and its Applications 415:133-140.

Consumer Financial Protection Bureau 2014. "Manufacturedhousing consumer finance in the United States.” Pp. 1-59 in Manufactured-housing consumer finance in the United States. Washington, DC: Consumer Financial Protection Bureau.

Covey, Stephen R. 1992. Principle Centered Leadership. New York, New York: Fireside.

Creswell, John W. 2014. Research Design. Thousand Oaks, California: Sage Publications, Inc.

Curtin, Nicola L., Joan M. Ostrove, and Abigail J. Stewart. 2011. "Social Class and Belonging: Implications for Graduate Students' Career Aspirations.” The Journal of Higher Education 82(6):748-774.

Dana, David A. 2009. “Exclusionary Eminent Domain.” Supreme Court Economic Review 17(1):7-62.

Desmond, Matthew. 2012. "Disposable Ties and the Urban Poor." American Journal of Sociology 117(5):1295-1335. 
Desmond, Matthew. 2012. "Eviction and the Reproduction of Urban Poverty.” American Journal of Sociology 118(1):88133.

Dirlam, Jonathan C. and David Jacobs. 2016. "Politics and Economic Stratification: Power Resources and Income Inequality in the United States 1." American Journal of Sociology 122(2):469-500.

Doherty, Michael E. and Elke M. Kurz. 1996. "Social Judgement Theory.” Thinking and Reasoning 2(2/3):109-140.

Duguid, Michelle M. and Melissa C. Thomas-Hunt. 2015. "Condoning Stereotyping? How Awareness of Stereotyping Prevalence Impacts Expression of Stereotypes.” Journal of Applied Psychology 100(2):343-359.

Edwards, John N., David L. Klemmack, and Louis Hatos Jr. 1973. "Social Participation Patterns among Mobile-Home and Single-Family Dwellers.” Social Forces 51(4):485-489. Retrieved September 10, 2016 (http://www.jstor.org/stable/2576695).

Federal Housing Finance Agency. 2016. "Enterprise Duty to Serve Underserved Markets - Final Rule.” Federal Housing Finance Agency. Retrieved April 4, 2017

(https://www.fhfa.gov/SupervisionRegulation/Rules/RuleDocu ments/2016\%20Duty\%20to\%20Serve\%20Final\%20Rule_For \%20Web.pdf).

French, Robert M. and Jeffrey K. Hadden. 1965. "An Analysis of the Distribution and Characteristics of Mobile Homes in America.” Land Economics 41(2):131-139. Retrieved September 10, 2016 (http://www.jstor.org/stable/3144267).

Friborg, Oddgeir, Monica Martinussen, and Jan H. Rosenvinge. 2006. "Likert-based vs. semantic differential-based scorings of positive psychological constructs: A psychometric comparison of two measuring of a scale measuring resilience.” Personality and Individual Differences 40:873-884.

Funke, Frederik and Ulf-Dietrich Reips. 2012. "Why Semantic Differentials in Web-Based Research Should Be Made from Visual Analogue Scales and Not from 5-Point Scales.” Field Methods 24(3):310-327. Retrieved September 9, 2016 (http://fmx.sagepub.com/). 
Griffin, Waylon D. and Frederick D. Sturdivant. 1973.

"Discrimination and Middle Class Minority Consumers."

Journal of Marketing 37(3):65-68. Retrieved September 9, 2016 (http://www.jstor.org/stable/1249949).

Harry, Joseph C. 2006. “"Trailer Park Trash": News, Ideology, and Depictions of the American Underclass.” Pp. 213-229 in Class and News. Lanham, Maryland: Rowman and Littlefield Publishers, Inc.

Hill, Ingrid. 1999. “A Poetics of Trailer Park Class.” Peace Review 11(2):225-230.

Hogg, Michael A. and Scott A. Reid. 2006. "Social Identity, SelfCategorization, and the Communication of Group Norms." Communication Theory 16:7-30.

Hoyt, G.C. 1954. "The Life of the Retired in a Trailer Park." American Journal of Sociology 59(4):361-370.

Hoyt, G. C. 1954. “The Process and Problems of Retirement.” The Journal of Business 27(2):164-168. Retrieved September 9, 2016 (http://www.jstor.org/stable/2350994).

Jefferson, Thomas 1776. "Declaration of Independence.” Philadelphia, Pennsylvania.

Jenkins, James J., Wallace A. Russell, and George J. Suci. 1958. "An Atlas of Semantic Profiles for 360 Words." The American Journal of Psychology 71(4):688-699. Retrieved September 9, 2016 (http://www.jstor.org/stable/1420326).

Jones, Trina. 2009. "Race, Economic Class, and Employment Opportunity.” Law and Contemporary Problems 72(4):57-87.

Judd, Charles M. and Bernadette Park. 1993. "Definition and Assessment of Accuracy in Social Stereotypes.” Psychological Review 100(1):109-128.

Katz, Daniel and Kenneth Braly. 1933. "Racial Stereotypes of One Hundred College Students.” The Journal of Abnormal and Social Psychology 28(3):280-290.

Kriegbaum, Katharina, Brandilynn Villarreal, Vinnie C. Wu, and Jutta Heckhausen. 2016. "Parents Still Matter: Patterns of Shared Agency With Parents Predict College Students' Academic Motivation and Achievement.” Motivation Science 2(2):97-115. 
Kumar, Deepa 2004. "Media, Class, and Power: Debunking the Myth of a Classless Society.” Pp. 6-21 in Class and News, edited by Don Heider. Lanham, Maryland: Rowman and Littlefield Publishers, Inc.

Latimer, Melissa and Rachael A. Woldoff. 2010. "Good Country Living? Exploring Four Housing Outcomes Among Poor Appalachians.” Sociological Forum 25(2):315-334. Retrieved September 10, 2016 (http://www.jstor.org/stable/40783396).

MacTavish, Katherine A. 2007. "The Wrong Side of the Tracks:

Social Inequality and Mobile Home Park Residence.”

Community Development: Journal of the Community

Development Society 38(1):74-91.

MacTavish, Katherine A., Megan L. Notter, and Devora Shamah. 2008. "Pathways toward Resilience among Women in Rural Trailer Parks.” Family Relations 57(5):613-624.

National Consumer Law Center. 2008. "Protecting Fundamental Freedoms in Communities.” Washington, D.C.

Newitz, Annalee and Matthew Wray 1997. "What is "White

Trash"? Stereotypes and Economic Conditions of Poor Whites in the United States.” Pp. 168-184 in Whiteness, edited by Mike Hill. $1^{\text {st }}$ ed. New York, New York: New York University Press.

Palmer, Jerry K. and Jonathan S. Gore. 2014. “A Theory of

Contrast Effects in Performance Appraisal and Social

Cognitive Judgments.” Psychol Stud 59(4):323-336.

Pickett, Kate and Richard Wilkinson. 2009. The Spirit Level. New York, New York: Bloomsbury Press.

Ritzer, George and Jeffrey Stepnisky. 2013. Contemporary

Sociological Theory and Its Classical Roots. $4^{\text {th }}$ ed. New York, New York: McGraw Hill.

Saatcioglu, Bige and Julie L. Ozanne. 2013. "Neighborhood, Moral Habitus and Status Negotiation in a Marginalized WorkingClass.” Journal of Consumer Research 40(4):692-710.

Siero, Frans W. and Bert J. Doosje. 1993. “Attitude change following persuasive communication: Integrating Social Judgement Theory and the Elaboration Likelihood Model.” European Journal of Social Psychology 23:541-554. 
Simon, Richard M. 2016. "The Conflict Paradigm in Sociology and the Study of Social Inequality: Paradox and Possibility.” Theory in Action 9(1).

Smith, James. 2002. "Race, Emotions, and Socialization.” Race, Gender \& Class 9(4):94-108.

Thompson, Craig and Kelly Tian. 2008. "Reconstructing the South: How Commercial Myths Compete for Identity Value through the Ideological Shaping of Popular Memories and Countermemories.” Journal of Consumer Research 34(5):595613.

Tighe, J R. 2012. "How Race and Class Stereotyping Shapes Attitudes Toward Affordable Housing." Housing Studies 27(7):962-983.

Worden, Rolfe A. 1963. “Zoning: Townships: Complete Exclusion of Trailer Camps and Parks.” Michigan Law Review 61(5):1010-1014.

Wrightsman, Lawrence S. 1992. Assumptions About Human

Nature: Implications for Researchers and Practitioners. $2^{\text {nd }}$ ed. Newbury Park, California: Sage Publications, Inc. 